\title{
Computer Aided System for Users with Visual Impairments
}

\author{
Sevgi Kirboyun \\ College of Education \\ Department of Disability and Psychoeducational Studies \\ University of Arizona \\ Tucson, Arizona \\ kirboyun@email.arizona.edu
}

\begin{abstract}
Screen readers enable people with visual impairment (VI) to have equal access to written information both on computers and smartphones. This paper presents an overview of screen readers that allow users with VI read the text materials and describe images on the computer screen by using a special software program to synthesize as speech. We study three aspects of the screen readers in terms of their accessibility. First, we invest on developing websites, apps, and software programs by following web content accessibility guidelines to ensure accessibility. We than conduct research on compatibility of the websites, apps, and software programs with screen readers. Last, we inform about descriptions of the images by creating alternative texts.
\end{abstract}

Keywords-screen readers, visual impairment, assistive technologies, mainstream devices component.

\section{INTRODUCTION}

According to the Individuals with Disabilities Education Act (IDEA) of 2004, assistive technology is defined as "any item, piece of equipment, or product system, whether acquired commercially off the shelf, modified, or customized, that is used to increase, maintain, or improve functional capabilities of individuals with disabilities". Over the past decade, advances in technology have provided new opportunities for people with VI to be independent at work, school, and home [13]. These advances have enabled users with VI to access written information as easily as their sighted peers [6].

Assistive Technology tools, such as screen readers, allow individuals with VI to follow the written text by reading written text on a computer screen aloud through a speech synthesizer [9]. For individuals with VI, screen readers are the most popular form of gaining access from mainstream devices like computers and cell phones. The use of such screen readers promotes the social interaction of people with VI, because of portability and inconspicuousness. For example, mobile phones and computers with screen readers can be used to scan text to enable people with VI to send email, read news, use navigation, and search websites [14]. Furthermore, screen readers also provide opportunities to develop specific interest areas for users with VI, such as reading, creating music scores, and learning foreign language(s). However, there are some software barriers that impact the usability of screen readers. The aim of this paper is to discuss advantages and barriers of using screen readers and suggest methods for improving accessibility of the content including testing compatibility, developing contents, and creating alternative texts for descriptions of images for individuals with VI.

\section{USE OF SCREEN READERS BY INDIVIDUALS WITH VISUAL IMPAIRMENTS}

People with VI use different screen readers based on platforms they need to work. Screen reader users input information into the computer by using QWERTY keyboard instead of using mouse. Keyboard shortcuts, which are used to navigate on the computer screen, work with most software, e.g., word processing programs, the web browsers, and electronic mail [12] on different operating systems such as Linux, Windows, and MacOS X, iOS, Android, and more. Some commonly used screen readers include Job Access with Speech (JAWS), NonVisual Desktop Access (NVDA), Window Eyes, VoiceOver and Talkback[12]. Among these ones, JAWS has been the most broadly used screen reader around the world as there exist many programs adapted for the use of it. Furthermore, JAWS supports for all popular Braille displays. Window Eyes is another screen reader available for Microsoft Windows operating system. Although sales of Window Eyes have ended, it is still one of the commonly used screen readers. NVDA is an open source and free screen reader for Windows, unlike the other tools. VoiceOver is a screen reader built into Apple computer operating systems. VoiceOver supports refreshable braille displays. Talkback is a screen reader on Android, which can also be used with Braille displays.

\section{BARRIERS OF USING SCREEN READERS}

There exist many challenges for the people with VI. For example, some platforms are not accessible to users with VI or existing softwares are incompatible with screen readers. Thus, not having complete access to the web and application content, with screen readers, excludes individuals with VI from obtaining the information presented in the digital media. For example, screen readers may not able to read the information on the screen, if the content is created with Flash. Therefore, developers must be aware of regarding to Flash content and accessibility when they design websites, applications, and software programs. Also, the lack of identification of inaccessible images has negative impact on accessing information by screen readers. Individuals with VI are unable to 
access the computer screen to interpret visual information such as pictures, drawings, and maps [5]. Since screen readers cannot translate a visual symbol or picture into auditory information automatically, it is difficult for individuals with VI to access content through icons like sighted people do [16]. For example, when a digital text is saved in PDF format with an image file, it is not possible for screen readers to read the text in the file.

\section{IMPROVING ACCESSIBILITY FOR INDIVIDUALS WITH VISUAL IMPAIRMENTS}

Individuals can gain access only if websites, applications, and software programs are compatible with screen readers. Therefore, it is significant to consider accessibility for users with VI when creating websites, applications, and software programs. If developers follow web content accessibility guidelines while creating websites and applications, the content of those websites and applications will be available for accessibility for all. There are several sources for web content accessibility guidelines, such as WebAIM, W3C, and AudioEye for developers. Similarly, to create accessible apps for screen reader users, there are many websites to guide for developers while creating new apps such as Developers, AppleVis and AbilityNet 20.

In addition, it is also beneficial for developers to have some first-hand experience with a screen reader. For example, AJAX (Asynchronous JavaScript and XML) is a great way of improving a web application to achieve a high level of user interactivity. Google Maps and Google Documents are highly common examples of AJAX applications. Hence, it would be useful to test the new web standards based AJAX widget in order to determine whether the information that is available visually is also available to the screen reader users [10].

When ensuring accessibility software programs, Microsoft Active Accessibility (MSAA) is an efficient tool that allows developers to support a wide variety of applications and it supplies a standard and consistent mechanism for compatibility between software programs and assistive technologies. There are many programs available for developers to use when testing MSAA such as Object Inspector (Inspect32), Accessible Event Watcher (Event32), Accessible Explorer (AccExplore), accProbe, aDesigner, and others [11].

Moreover, another approach to improve access to visual information is that each image must be described with alternative text (alt text) in web pages or digital documents with a verbal description about the content and function of the image. This allows users of screen readers to understand information about the image.

\section{DisCUSSIONS}

It is essential that software developers continue to work on making software as accessible as they can for a wide range of people. It should be considered that testing the accessibility of websites and software programs will be necessary to provide the actual accessibility to the digital media for individuals with VI as well. Developers need to consider the screen reader experience when they create websites and digital texts. Developing technologies that eliminate the barriers to accessibility is vital to turn disadvantages to advantages for all individuals in their quest for access equal to information.

\section{REFERENCES}

[1] C. R. Farnsworth, and J. L Lucker, "The impact of assistive technology on curriculum accommodation of a Braille-reading student," RE:view, vol. 39, pp. 171-187, 2008.

[2] B. J. Edwards, and S. Lewis, "The use of technology in programs for students with visual impairments in Florida," Journal of Visual Impairment and Blindness, vol. 92, pp. 302- 306, 1998.

[3] L. H. Boyd, W. L. Boyd, and G. C. Vanderhelden, "The graphical user interface: Crisis, danger, and opportunity," Journal of Visual Impairment \& Blindness, vol. 84, pp. 496-502, 1990.

[4] S. Burgstahler, Working together: Computers and people with sensory impairments. Seattle, WA: Disabilities, Opportunities, Internetworking and Technology Project, 2001. [Online]. Available: ERIC

[5] K. S. Segers, "Assistive technology for students with visual impairments: In-service teacher training and its relationship to student access and usage across academic subject areas," P.h.D dissertation, Capella University, 2014.

[6] E. Gerber, "The benefits of and barriers to computer use for individuals who are visually impaired," Journal of Visual Impairment \& Blindness, pp. 536-550, September 2003.

[7] M. A. Mulloy, C. Gevarter, M. Hopkins, K. S. Sutherland, and S. T. Ramdoss, "Assistive technology for students with visual impairments and blindness," In Assistive technologies for people with diverse abilities, New York: Springer, pp. 113-156, 2014.

[8] S. M. Kelly, and G. A. Kapperman, "Second look at what high school students who are blind should know about technology," Journal on Technology \& Persons with Disabilities, vol. 6, pp. 385-398, 2018.

[9] American Foundation for the Blind, "Screen readers," [Online]. Available: http://www.afb.org/prodBrowseCatResults.aspx?CatID=49

[10] S. Faulkner, "NVDA- A free and open source screen reader for Windows," [Online] Available:

http://www.developer.paciellogroup.com/blog/2008/01/nvda-a-free-andopen-source-screen-reader-for-windows/ [Accessed: 2008].

[11] J. Avila, "Looking for object inspector and other MSAA tools? Level Access," [Online]. Available:

https://www.levelaccess.com/looking-for-object-inspector-and-othermsaa-tools/ [Accessed: 2010].

[12] WebAIM. "Screen Reader User Survey," [Online]. Available: http://www.webaim.org/projects/screenreadersurvey6. [Accessed: 2015].

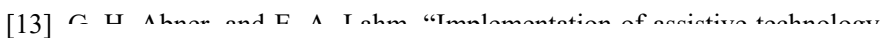
with students who are visually impaired: Teachers' readiness," Journal of Visual Impairment \& Blindness, vol. 96, pp. 98-105, 2002.

[14] I Donlrar D Thaman $F$ Duhin and A Mnhlmann-Nonn "Nution1 reading aids for children and young people with low vision," The Cochrane Library, 2015.

[15] The Individuals with Disabilities Education Act (IDEA) of 2004,§ 300.5 Assistive technology device, (2004).

[16] L. H. Boyd, W. L. Boyd, and G. C. Vanderhelden, "The graphical user interface: Crisis, danger, and opportunity," Journal of Visual Impairment \& Blindness, vol. 84, pp. 496-502, 1990. 